\title{
Medical Imaging and FDA Regulatory Pathway for Radiology devices
}

\author{
Sunil Aggarwal* and Somya Aggarwal \\ Independent scholars, New York, USA
}

Submission: October 20, 2016; Published: October 22, 2016

*Corresponding author: Sunil Aggarwal, MD, MBA, New York, USA, Tel: 1-717-622-1264; Email: drsunilaggarwal@gmail.com

\begin{abstract}
The medical imaging arena is fast developing and changing from the days of simple X-rays to advanced MRI imaging. Radiological imaging is very important in the targeted, clinical diagnosis and management of patients, may it be Ultrasound, CT scan or MRI and needs continuous evolution. Continuous evolving and developing medical imaging technologies need state- of -the art quality assurances and regulations as they are used on patients in every possible diagnosis. FDA's Center for devices and radiological health (CDRH) is the regulatory body in US that is required to clear medical imaging therapeutic and diagnostic radiological devices intended to enter the market for sale.
\end{abstract}

Keywords: Medical imaging; Regulation; FDA; 510(K); Substantially equivalent

Abbreviations: CT: Computed Tomography; MRI: Magnetic Resonance Imaging, FDA: Food and Drug Administration; PMA: Premarket Approval

\section{Introduction}

Medical imaging devices have, generally, been classified into Class I or Class II categories of medical devices. These imaging devices are considered medical devices through the FD\& C act (Federal Food, Drug and Cosmetic Act) with amendments through Medical device amendments of 1976 and other amendments [1-4]. Some devices that were classified into other categories could get reclassified into a simpler class based on their safety data. Radiological device manufacturers must keep in mind on a predicate device whenever they are looking for a Class I or Class II category advancement but keeping the safety and indications as such.. Increasing usefulness by eliminating defects and waste from a medical imaging device by quality processes such as lean is always helpful [5].

\section{Medical Imaging -Routes for Regulation}

Generally, the medical imaging devices fall under the category of non - 501(k) - exempt class and class II. Thus these imaging devices can follow the route of $510(\mathrm{k})$ and need not enter PMA pathway [6]. There have been exceptions though. Digital mammography required to go through a PMA pathway by FDA [7]. This was based on its indication of use and its novel technology. Whether this category changes in future is to be seen.

Helical CT scan got a class II clearance from FDA for marketing. This was determined after considering the conventional CT scanners as a predicate to the helical devices in terms of its being substantially equivalent to the existing conventional CT technology. The safety and efficacy of helical CT was also deemed to be equivalent to conventional CT that were marketed in 1976 and thought to be pre-1976 products as they were developed in 1960 and came to the market in 1976.Getting a clearance letter from FDA on $510(\mathrm{~K})$ for a medical imaging device is a milestone and the ultimate goal for any medical device manufacturer for the innovation and timely introduction to the market.

\section{Radiological Devices- Types}

Radiological medical devices can be classified as two types: One using ionizing radiation and the other kind not using ionizing radiation

\section{Medical imaging devices using ionizing radiation}

These devices are mostly Class 1- 500(k) exempt (X-Ray tube housings) to Class II non $500(\mathrm{k})$ exempt (X-Ray imagers). These imaging devices have undergone historical development as they were cleared via $510(\mathrm{k})$ route using conventional X-ray machines as a predicate.

\section{Medical imaging devices not using ionizing radiation}

Ultrasonography existed prior to 1976 and entered market as a Class II device. This incorporated various substantial 
developments in ultrasound scanners as it got cleared through $510(\mathrm{k})$ process. Its evolution of transducers, 3D imaging, color Doppler, internal and external use were all part of Class II clearance via $510(\mathrm{k})$.

MRI, on the other hand, did not exist prior to 1976 and entered market as a Class III device following a PMA. Later, based on its safety data and widespread use, it was transferred to a Class II device in 1988.

\section{Medical devices Amendments of 1976 and Food and Drug Administration Modernization Act of 1997- Basic difference}

Medical devices Amendments of 1976 were made to ensure that all the medical devices are safe and effective for their intended use and indications $[8,9]$.

Food and Drug Administration Modernization Act of 1997, on the other hand, does not change the safety requirement for its intended use of a medical device, but these amendments build on regulatory efficiency with the help of administrative reforms. The idea is to improve the evaluation process and make it more efficient.

\section{Medical Imaging Device Recall and Adverse Event Reporting}

Recalls are usually made by the manufacturers themselves, whenever they notice a product to be removed or corrected from the market. Title 21 of the Code of federal Regulations (parts 7.41-7.59) is important for the knowledge of recall by the company or such device manufacturers, who make a decision to recall a device from the market, voluntarily. A ten day period is given to such manufacturers to inform FDA about the recall. Rarely, FDA may use its power to recall when a recall is necessary and not done through its manufacturer. Maintaining quality by effective elimination of errors and waste can help in minimizing recalls [5].

Similarly, adverse events must be reported to FDA through its various reporting platforms such as Med Watch or, Med Sun [10] or by voluntary reports from patients and end users.

\section{Conclusion}

Based on the historic al data for medical imaging devices, it has been a straightforward path via $510(\mathrm{k})$ and those led to various advancement to the predicate device and weresubstantially equivalent. Some of these imaging devices were either exempt from $510(\mathrm{k})$ or were in Class II category of $510(\mathrm{k})$ pathway. However, all medical imaging devices are not always in these two categories and may be thought of as a different class or de-novo by FDA and device manufacturers must be ready with the clinical data to support their PMA or reclassification of the imaging device. Since FDA regulates both safety and efficacy, in comparison to European CE approval standards that regulates only safety and not efficacy, it is more time consuming in US regulatory approval process. This causes a significant delay in the approval of new medical devices in United States.

\section{References}

1. Smith JJ (2001) Regulation of Medical Devices in Radiology: Current Standards and Future Opportunities. Radiology 218(2): 329-335.

2. Pietzsch JB, Aquino LM, Yock PG, Pate-Cornell M, Linehan JH (2007) Review of U.S. Medical Device Regulation. ASME J Med Devices 1(4): 283-292.

3. Pietzsch JB, Zanchi MG, Linehan JH (2012) Medical Device Innovators and the $510(\mathrm{k})$ Regulatory Pathway: Implications of a Survey-Based Assessment of Industry Experience. ASME J Med Devices 6(2): 021015.

4. Medical Device Amendments of 1976 (1976). Public Law 94-295.

5. Sunil A, Sanju A, Somya A (2016) A Study of Lean in Oncology: Reducing Waste and Increasing Value. Canc Therapy \& Oncol Int J 1(3): 555-563.

6. Kaplan AV, Baim DS, Smith JJ, Feigal DA, Simons M, et al. (2004) Medical device development from prototype to regulatory approval. Circulation 109(25): 3068-3072.

7. Nields MW (2010) FDA \& digital mammography: why has FDA required full field digital mammography systems to be regulated as potentially dangerous devices for more than 10 years? Acad Radiol 17(5): 652657.

8. 21 USC $§ 3939$.

9. Food and Drug Administration Modernization Act of 1997 (1997). Public Law 105-115.

10. Mandatory Reporting Requirements: Manufacturers, Importers and Device User Facilities. US Food and Drug Administration. 